\title{
Basic Hydrolysis of Fullerene-based Esters: A Tiny Step Away from Nucleophilic Addition to Fullerene
}

\author{
Janez Cerar and Janez Cerkovnik* \\ Faculty of Chemistry and Chemical Technology, University of Ljubljana, \\ Večna pot 113, SI-1000 Ljubljana, Slovenia. \\ *Corresponding author: E-mail: janez.cerkovnik@fkkt.uni-lj.si
}

Received: 18-02-2015

Dedicated to prof. Jože Koller on the occasion of his $70^{\text {th }}$ birthday.

\begin{abstract}
Direct nucleophilic addition of $-\mathrm{OH}$ groups on the $\mathrm{C}_{60}$ skeleton in the basic hydrolysis of ethyl ester of $T_{\mathrm{h}}$-symmetric fullerenehexamalonic acid ( $T_{\mathrm{h}}$-FHMA), leading to the formation of a hybrid with features of $T_{\mathrm{h}}$-FHMA and fullerenol, has been observed as an important side reaction. The hydroxylation takes place at considerably milder conditions as those usually used in the synthesis of $\mathrm{C}_{60}$ fullerenols. UV/Vis and IR spectroscopy were successfully used as a fast monitoring tool which might be of help also in other investigations where additions on $\mathrm{C}_{60}$ skeleton of molecules with distinct absorption spectra take place.
\end{abstract}

Keywords. $T_{\mathrm{h}}$-symmetric Fullerenehexamalonic acid, fullerenol, basic hydrolysis, UV/Vis spectrophotometry, IR spectroscopy

\section{Introduction}

Since the discovery of fullerenes many attempts have been made to synthesize not only per se structurally attractive fullerene-based compounds but also compounds that could be applied for technological ${ }^{1}$ or biological ${ }^{2}$ purposes. Although in a recent decade scientists also discovered other nanostructured materials besides fullerene, there are still some areas where perfectly spherical cage of $\mathrm{C}_{60}$ offers possibilities that can be hardly superseded by other molecules. One of such topics is investigation of properties of solutions of highly charged particles where salts of $T_{\mathrm{h}}$-symmetric fullerenehexamalonic acids $\left(T_{\mathrm{h}}\right.$ $\mathrm{C}_{66}(\mathrm{COOH})_{12}$, in further text denoted as $T_{\mathrm{h}}$-FHMA ) are almost ideal model compounds. ${ }^{3-6}$ It is not only that $\mathrm{C}_{60}$ 's spherical shape significantly facilitates calculation of electrostatic field around the functionalized molecule; ${ }^{7,8}$, in numerous cases rigidity of its skeleton is equally important as well as exactly defined number of ionizable functional groups in the molecule. ${ }^{5}$ The synthesis of welldefined $T_{\mathrm{h}}$-FHMA sample, however, is accompanied with serious difficulties. The most troublesome is the final step of the synthesis where, during the hydrolysis of $T_{\mathrm{h}}$-FHMA ester into its salt, partial decarboxylation as a side reaction was observed. ${ }^{9}$
There also exist other water-soluble fullerene compounds but they are either less water-soluble or cannot be prepared pure enough to be utilized in studies where working with well-defined samples is of utmost importance. Among the latter compounds one has to certainly mention polyhydroxylated fullerenes, denoted more popularly as fullerenols or fullerols. Their preparation is much easier than the preparation of $T_{\mathrm{h}}$-FHMA and it is of no surprise that publications concerning fullerenols are far more numerous $^{10}$ than those concerning $T_{\mathrm{h}}$-FHMA. The research work related to fullerenols embraces wide spectrum of areas, e.g., studies of their electrolytic properties, ${ }^{11}$ physicochemical characterization of their properties in water ${ }^{12}$ and use in catalytic processes, ${ }^{13}$ studies related to their application in drug delivery ${ }^{14}$ and their biological activity. ${ }^{15}$ Due to the popularity of fullerenols there still exists a need for improving the synthesis ${ }^{16}$ and analytical methods for establishing their characterization. ${ }^{17}$

During our recent attempts to further optimize hydrolysis of ethyl ester of $T_{\mathrm{h}}$-FHMA we have observed that under certain conditions a nucleophilic addition of $-\mathrm{OH}$ groups to fullerene $\mathrm{C}_{60}$ cage takes place as a side reaction, leading to the formation of some kind of a hybrid with features of $T_{\mathrm{h}}$-symmetric FHMA and fullerenol (Scheme 1). 

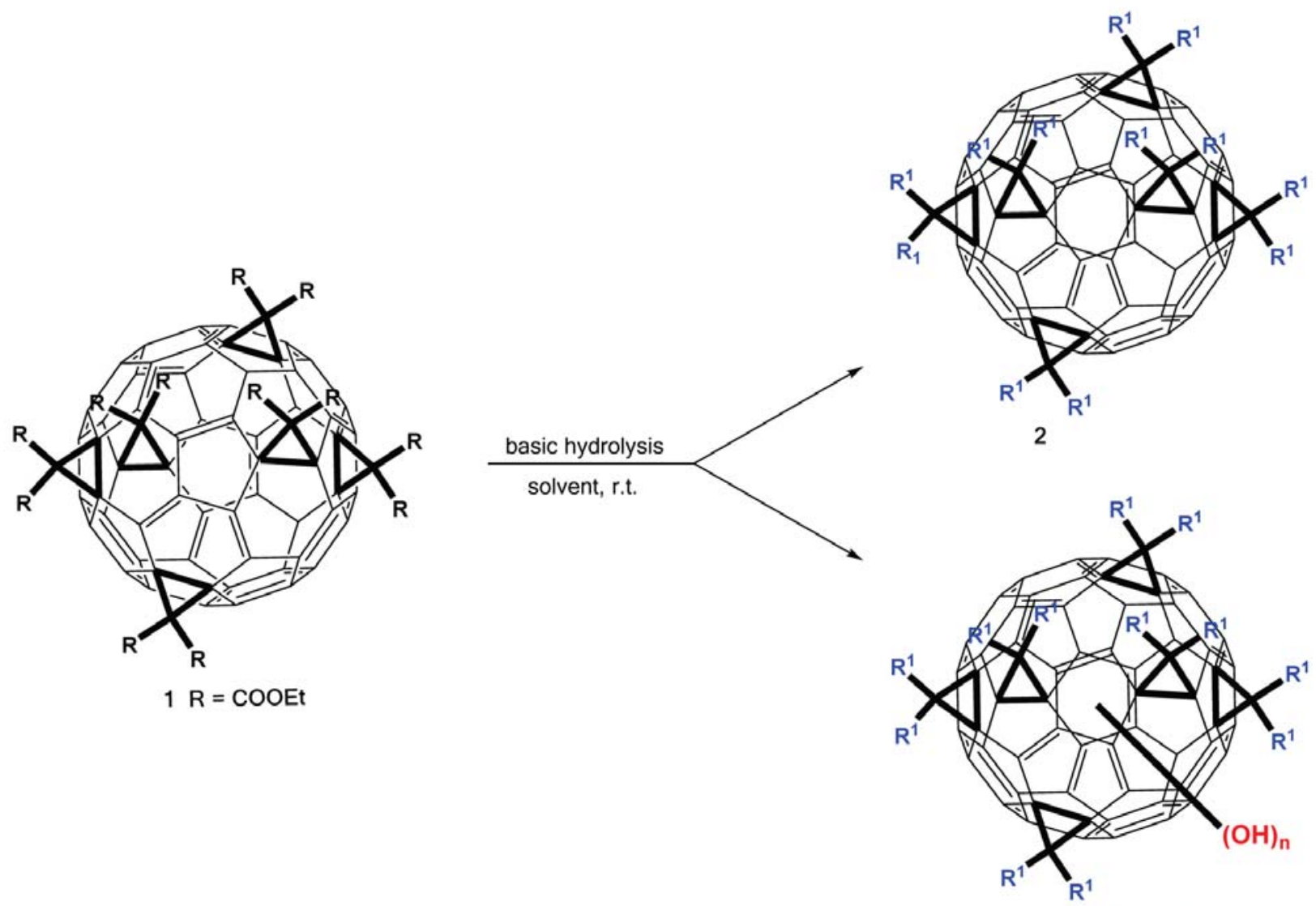

$3 \mathrm{R}^{1}=\mathrm{COOH}$

Scheme 1. Hydrolysis of ethyl ester of $T_{\mathrm{h}}$-FHMA (1) producing $T_{\mathrm{h}}$-FHMA (2) and a hybrid (3) between $T_{\mathrm{h}}$-FHMA and fullerenol.

\section{Experimental}

\section{1. Materials and General Synthetic Procedures}

Ethyl ester of $T_{\mathrm{h}}$-FHMA was synthesized according to the literature procedure. ${ }^{18}$ We have used $\mathrm{C}_{60}(99.5+\%$ purity), supplied by MER Corporation (USA), 9,10-dimethylanthracene (99\%, Aldrich), 1,8-diazabicyclo[5,4,0]undec-7-ene (98\%, Aldrich), and diethyl bromomalonate (95\%, Merck). Reaction product was purified by column chromatography using $\mathrm{SiO}_{2}$ as a stationary phase (Kieselgel 60, 0.043-0.060 mm), and toluene/ethyl acetate mobile phase $(95: 5 \mathrm{v} / \mathrm{v}$ at the beginning, and 88:12 v/v at the end of the chromatographic separation). Final purification of the product was made by precipitation of $T_{\mathrm{h}}-\mathrm{C}_{66}(\mathrm{COOEt})_{12}$ from a concentrated chloroform solution by dropping it into hexane. Identity and purity of the isolated $T_{\mathrm{h}}-\mathrm{C}_{66}(\mathrm{COOEt})_{12}$ was confirmed by thin layer chromatography on $\mathrm{SiO}_{2}$ stationary phase (mobile phase: toluene/ethyl acetate 95:5 v/v; $R_{\mathrm{f}}$ $=0.24)$ and by ${ }^{1} \mathrm{H}$ and ${ }^{13} \mathrm{C}$ NMR spectra. ${ }^{18}$

Hydrolysis of $T_{\mathrm{h}}-\mathrm{C}_{66}(\mathrm{COOEt})_{12}$ with $\mathrm{KOH}$ in acetone (Procedure 1). $19.8 \mathrm{mg}$ of $T_{\mathrm{h}}-\mathrm{C}_{66}(\mathrm{COOEt})_{12}$ was dissol- ved in $70 \mathrm{~mL}$ of acetone at room temperature to give clear bright yellow solution. During stirring of $T_{\mathrm{h}}-\mathrm{C}_{66}(\mathrm{COOE}-$ t) ${ }_{12}$ solution, $0.33 \mathrm{~mL}$ of $0.5 \mathrm{M}$ aqueous solution of $\mathrm{KOH}$ (approx. 30\% excess according to the quantity of carboxylic groups in the substrate) was added into the acetone solution. The solution became turbid immediately and in 1-2 minutes turned from yellow into clear dark-brownish solution. After 5 minutes additional $50 \mu \mathrm{L}$ of $0.5 \mathrm{M} \mathrm{KOH}$ were added and stirred for additional 15 minutes. During this time the brownish color of the solution intensifies. At the end, the solvent was removed by evaporation at reduced pressure and the reaction product was analyzed without further purification.

Hydrolysis of $T_{\mathrm{h}}-\mathrm{C}_{66}(\mathrm{COOEt})_{12}$ with an equimolar amount of NaOMe in acetone (Procedure 2). The same amounts of substrate and solvent were used as in previous experiment, except of using methanol solution of $\mathrm{NaOMe}(0.6 \mathrm{~mL} \mathrm{MeOH}$ and $3.5 \mathrm{mg} \mathrm{Na})$ as the basic reagent, which was slowly added by dropping. At the end of the reaction, additional $10 \%$ of the original amount of $\mathrm{NaOMe}$ was added to ensure completion of the reaction. The solution became turbid immediately and turned from yellow into clear moderate brownish solution. 
Finally, the solvent was removed by evaporation at reduced pressure.

Hydrolysis of $T_{\mathrm{h}}-\mathrm{C}_{66}(\mathrm{COOEt})_{12}$ with an equimolar amount of $\mathbf{N a O M e}$ in toluene/ $\mathbf{C H}_{\mathbf{2}} \mathbf{C l}_{\mathbf{2}}$ (Procedure 3a). $19.8 \mathrm{mg}$ of $T_{\mathrm{h}}-\mathrm{C}_{66}(\mathrm{COOEt})_{12}$ was dissolved in $0.5 \mathrm{~mL}$ of dichloromethane and stirred with $20 \mathrm{~mL}$ of toluene at room temperature to give clear bright yellow solution. Into this solution, the methanol solution of $\mathrm{NaOMe}(0.6$ $\mathrm{mL} \mathrm{MeOH}$ and $3.5 \mathrm{mg} \mathrm{Na}$ ) was slowly added by dropping. At the end of the reaction, additional $10 \%$ of the original amount of $\mathrm{NaOMe}$ was added to ensure completion of the reaction (sodium salt, $T_{\mathrm{h}}-\mathrm{C}_{66}(\mathrm{COONa})_{12}$, should precipitate from toluene/ $\mathrm{CH}_{2} \mathrm{Cl}_{2}$ solution). The yellow precipitate was isolated from the supernatant by centrifugation and dried under reduced pressure. Dry sample was dissolved in triple distilled water and passed slowly through cationic ion exchange resin in $\mathrm{H}^{+}$form (Amberlite 200) in order to remove sodium ions.

Hydrolysis of $T_{\mathrm{h}}-\mathrm{C}_{66}(\mathrm{COOEt})_{12}$ using an excess of NaOMe in toluene/ $\mathrm{CH}_{2} \mathrm{Cl}_{2}$ (Procedure 3b). $1.13 \mathrm{~g}$ of $T_{\mathrm{h}}-\mathrm{C}_{66}(\mathrm{COOEt})_{12}$ was dissolved in $50 \mathrm{~mL}$ of dichloromethane and slowly poured into $700 \mathrm{~mL}$ of toluene at room temperature, during the intense mixing, to give clear bright yellow solution. Methanol solution of NaOMe (20 $\mathrm{mL} \mathrm{MeOH}$ and $208 \mathrm{mg} \mathrm{Na}$ ) was added by dropping to the $T_{\mathrm{h}}-\mathrm{C}_{66}(\mathrm{COOEt})_{12}$ solution within one minute and the reaction was allowed to proceed for 130 minutes. At the end of the reaction, the product was precipitated while the solution turned colorless. Reaction mixture was filtered through filter paper to isolate the fine precipitate. The product was washed first with toluene and then with hexane, and finally dried under reduced pressure overnight. Dry sample was dissolved in triple distilled water and sodium ions were exchanged for $\mathrm{H}^{+}$ions on cationic ion exchange resin in $\mathrm{H}^{+}$form (Amberlite 200).

Hydrolysis of $T_{\mathrm{h}}-\mathrm{C}_{66}(\mathrm{COOEt})_{12}$ using an excess of NaOMe in toluene/ $\mathrm{CH}_{2} \mathrm{Cl}_{2}$ (Procedure 3c). This procedure was performed in the same way as Procedure $\mathbf{3 b}$, except that smaller quantities of $T_{\mathrm{h}}-\mathrm{C}_{66}(\mathrm{COOEt})_{12}$ were used (see Procedure 3a). Obviously, the outcome of the hydrolysis reaction critically depends on the volume of dichlorometane used for dissolving the starting $T_{\mathrm{h}}$ $\mathrm{C}_{66}(\mathrm{COOEt})_{12}$ before adding toluene.

Preparation of fullerenol. Fullerenol was prepared according to the literature procedure ${ }^{19}$ and it is assumed that fullerenol, prepared by following this procedure, has around $26-\mathrm{OH}$ groups attached to the $\mathrm{C}_{60}$ skeleton.

\section{2. Instruments}

UV/Vis spectra were recorded on Cary 100 instrument (Varian, USA). Aqueous solutions of fullerenes were measured in quartz cuvettes of various light paths, depending on the concentration and molar absorption coefficients of solutes. Double beam mode was applied and baseline was substracted from the measured signal. Measurements were carried out at $25.0^{\circ} \mathrm{C}$. ATR-IR spectra were recorded on Bruker Alpha-Platinum spectrometer.

\section{Results and Discussion}

The most critical step in the synthesis of $T_{\mathrm{h}}$-FHMA (2, Scheme 1) is hydrolysis of ester groups in $T_{\mathrm{h}}$ $\mathrm{C}_{66}(\mathrm{COOEt})_{12}(\mathbf{1}$, Scheme 1$)$. We have already devoted a great deal of attention to this reaction, focusing primarily on partial decarboxylation. ${ }^{9}$ During our previous preparations of $T_{\mathrm{h}}$-FHMA we have already observed that bright yellow color of $T_{\mathrm{h}}-\mathrm{C}_{66}(\mathrm{COOEt})_{12}$ slightly changed into a bit more brownish color after hydrolysis with $\mathrm{NaOMe}$. Nevertheless, the characteristic shape of UV/Vis spectra of solutions of $T_{\mathrm{h}}$-FHMA remained almost the same (see for example Figure 1, Procedure 3a), as it is known for other $T_{\mathrm{h}}$-symmetric adducts. ${ }^{20,21}$, We ascribed small changes in the shape of the spectra to the solvent effect (changing from toluene to water) and the charge acquired on the carboxylic groups. During our recent experiments with basic hydrolysis, presented here, far more drastic change of color from yellow to brown was seen during hydrolysis of the $T_{\mathrm{h}}-\mathrm{C}_{66}(\mathrm{COOEt})_{12}$ with $\mathrm{KOH}$ in acetone (Figure 1, Procedure 1). Our observation was confirmed by recording $\mathrm{UV} / \mathrm{Vis}$ spectrum of the reaction product. A notable change of the shape of the spectrum, compared to the spectra obtained in earlier hydrolysis reactions, was observed. The spectrum of hydrolized product, obtained with $\mathrm{KOH}$ in acetone, shows increased intensity in the region of visible light, while the shape of the spectrum below $350 \mathrm{~nm}$ lost the pattern characteristic of $T_{\mathrm{h}}$-symmetric hexakis adducts and became more similar to the one of fullerenol (see Figure 1).

As can be seen from Figure 1, UV/Vis absorption spectra of $T_{\mathrm{h}}-\mathrm{C}_{66}(\mathrm{COOEt})_{12}$, hydrolyzed by NaOMe in toluene $/ \mathrm{CH}_{2} \mathrm{Cl}_{2}$ solution, retained their characteristic pattern of $T_{\mathrm{h}}$-symmetric hexakis adducts (Procedure $3 \mathrm{a}$ ). ${ }^{20,21}$, Use of the same base $(\mathrm{NaOMe})$ in acetone qualitatively preserved the same but rather less pronounced shape, typical of $T_{\mathrm{h}}$-symmetric hexakis adducts (Procedure 2). It is interesting to mention that Arrais and coworkers synthesized water-soluble oxygenated products of $\mathrm{C}_{60}$ using tetrahydrofurane as solvent by adding $\mathrm{Na} / \mathrm{K}$, isopropanol and water. ${ }^{22}$ Based on the results of analysis, authors concluded that by applying this procedure, the most preferable reaction in this case is the addition of $-\mathrm{OH}$ groups to the fullerene skeleton. ${ }^{22}$

The most notable change in our UV/Vis spectra, observed when hydrolysis with $\mathrm{NaOMe}$ was done in acetone, is the diminished depth of the local minimum at 258 $\mathrm{nm}$. When hydrolysis was carried out in acetone by using 


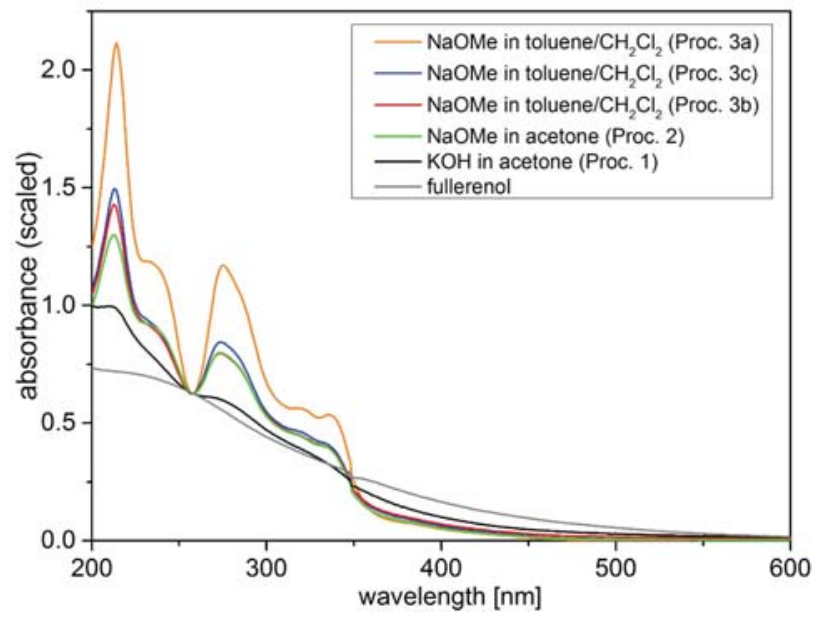

Figure 1. UV/Vis absorption spectra of samples hydrolyzed at different conditions. Spectra were recorded in water at $25^{\circ} \mathrm{C}$ and linearly scaled to have the same absorbance at $258 \mathrm{~nm}$ (local minimum in spectra of low deteriorated samples; chosen arbitrary as a reference point). Discontinuity of spectra at $350 \mathrm{~nm}$ is due to the change of light source in the spectrophotometer. The concentration of fullerene species in all solutions was of the range $10^{-5} \mathrm{~mol}_{\mathrm{Ful}} / \mathrm{L}$.

$\mathrm{KOH}$ as a base, the UV/Vis spectrum of the product dramatically changed and is hardly comparable to the spectrum which is representative for $T_{\mathrm{h}}$-symmetric hexakis compounds. Namely, it is characteristic for $T_{\mathrm{h}}$-symmetric hexakis adducts that due to the reduced conjugation (there are eight isolated benzenoid rings left on the fullerene cage) they demonstrate only minimal absorption in the region of visible light, tailing until $460 \mathrm{~nm} \cdot{ }^{20}$ Moreover, comparison of spectra of various $T_{\mathrm{h}}$-symmetric hexakis adducts, presented by Diederich ${ }^{20}$ and by Lamparth ${ }^{21,23}$, shows a common feature of such spectra: a distinctive local absorption minimum at $\approx 260 \mathrm{~nm}$ surrounded by two pronounced absorption peaks, and a shoulder in the region between 320 and $340 \mathrm{~nm}$. Such UV/Vis spectra are typical for all hexakis adducts because of the same conjugation left on the $\mathrm{C}_{60}$ skeleton, and are almost independent on the type of the addend.

On the contrary, the UV/Vis spectrum of fullerenol shows no absorption peaks in the range between 190 and $900 \mathrm{~nm}^{24}$ and its molar absorption coefficient monotonically increases with decreasing wavelength (Figure 1). ${ }^{12}$ Obviously, the recorded absorption spectrum of the reaction product, obtained by the basic hydrolysis with $\mathrm{KOH}$ in acetone, can be regarded as a hybrid spectrum of $T_{\mathrm{h}}$ symmetric hexakis adduct and fullerenol (Figure 1, Procedure 1). These facts also explain why hydroxylation occurring in $T_{\mathrm{h}}$-symmetric hexakis adducts can be observed by bare eyes, if the degree of hydroxylation is high enough.

Unfortunately, we were unable to determine the exact degree of hydroxylation of obtained reaction products by the use of elemental analysis. Use of more direct mass spectrometric identification method (ESI MS) also failed to unambiguously determine the reaction products. Namely, although LC-MS methods are a powerful tool for the quantization of fullerenes in complex samples, these techniques alone cannot provide detailed qualitative information. $^{25}$

Due to the presence of six malonic addends on the $\mathrm{C}_{60}$ skeleton, one may expect that the number of $-\mathrm{OH}$ groups will be smaller than in the case of pure fullerenol (i.e., 26) ${ }^{19}$ Furthermore, the presence of residual water molecules and possible partial decarboxylation ${ }^{9}$ additionally increases uncertainty of the molecular mass calculations from the measured hydrogen quantity. Additional source of error could also come from the presence of residual alkali metal ions $\left(\mathrm{Na}^{+} / \mathrm{K}^{+}\right)$in the sample. It is possible to diminish the quantity of these ions to a certain extent by the application of a gel-filtration. However, the determination of the number of $-\mathrm{OH}$ groups requires both tedious work and application of numerous analytical techniques, too expensive even in the case of pure fullerenol. ${ }^{26}$ In order to assure complete removal of alkaline ions, the reaction product should be transformed into an acidic form on a strongly acidic ion exchange resin. Still, this provokes deterioration of the reaction product, probably due to the transformation of the vicinal hydroxy groups to the corresponding ketone structure, ${ }^{19}$ thus changing the amount of hydrogen atoms present in the sample. Similar uncertainties, as met in the interpretation of the results of elemental analysis, are also valid for the interpretation of ${ }^{1} \mathrm{H}$ NMR spectrum. While the latter technique is rather sensitive to the presence of reactants (e.g. tetrabutylammonium hydroxide) used in the synthesis of fullerenols ${ }^{26}$ it is of no practical help when physico-chemical characterization of fullerenol and its by-products is in question. ${ }^{17}$ Therefore, such spectra can be used only as an additional support for assumed hydroxylation, rather than an argument against it.

Due to the low sensitivity of the ${ }^{13} \mathrm{C}$ NMR spectroscopy and increased asymmetry on the $\mathrm{C}_{60}$ skeleton imposed by hydroxylation and/or partial decarboxylation of the FHMA, ${ }^{9}$ this technique would be of questionable help.

Consequently, besides UV/Vis spectra, the most promising tool for the identification of the changes during the hydrolysis of the $T_{\mathrm{h}}-\mathrm{C}_{66}(\mathrm{COOEt})_{12}$, that induced the color change, seems to be IR spectra. The comparison of IR spectra of fullerenol and reaction products of the hydrolysis of $T_{\mathrm{h}}-\mathrm{C}_{66}(\mathrm{COOEt})_{12}$ at different conditions, together with the IR spectrum of the parent $T_{\mathrm{h}}-\mathrm{C}_{66}(\mathrm{COOE}-$ t) ${ }_{12}$ is shown in Figure 2.

IR spectrum of the parent ester, $T_{\mathrm{h}}-\mathrm{C}_{66}(\mathrm{COOEt})_{12}$ (Figure 2, spectrum 1), contains typical $\mathrm{C}=\mathrm{O}$ absorption at $1750 \mathrm{~cm}^{-1}$ in contrast to the IR spectrum of fullerenol (Figure 2, spectrum 5) containing a broad $\mathrm{OH}$ absorption band at $3200 \mathrm{~cm}^{-1}$, together with three typical strong and broad absorptions in the fingerprint region between 1000 and $1700 \mathrm{~cm}^{-1}$. The IR spectra of the different samples of 


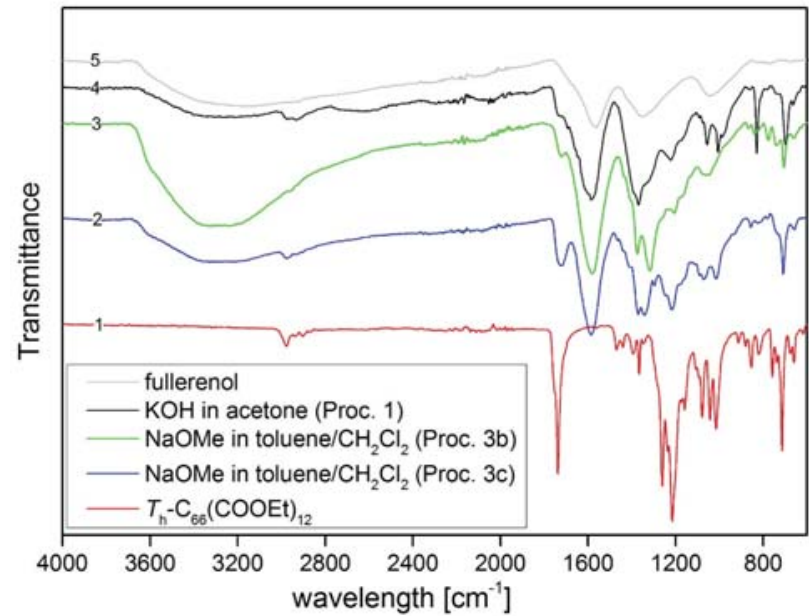

Figure 2. IR spectra of hydrolyzed samples of $T_{\mathrm{h}}-\mathrm{C}_{66}(\mathrm{COOEt})_{12}$ at different conditions, together with the spectrum of the parent sample.

hydrolyzed $T_{\mathrm{h}}-\mathrm{C}_{66}(\mathrm{COOEt})_{12}$ (Figure 2 , spectra 2-4) contain broad $\mathrm{OH}$ absorption bands at $3200 \mathrm{~cm}^{-1}$ and, in line with the use of stronger bases for the hydrolysis of $T_{\mathrm{h}}$ $\mathrm{C}_{66}(\mathrm{COOEt})_{12}$, such as $\mathrm{KOH}$ in acetone (spectrum 4), typical fingerprint absorptions appeared, very similar to the absorptions in the spectrum of fullerenol (spectrum 5). As in the case of the UV/Vis spectra, one could safely assume that IR spectra of hydrolyzed samples of $T_{\mathrm{h}}$ $\mathrm{C}_{66}(\mathrm{COOEt})_{12}$ represent a hybrid spectrum of $T_{\mathrm{h}}$-FHMA and fullerenol.

A practical question that arises from our experiments could be whether it is possible to safely hydrolyse $T_{\mathrm{h}}-\mathrm{C}_{66}(\mathrm{COOEt})_{12}$ at basic conditions, not to risk the hydroxylation of the $\mathrm{C}_{60}$ skeleton. One possible hint would be that small $\mathrm{OH}^{-}$ions experience less steric obstacles than larger $\mathrm{MeO}^{-}$ions and can therefore penetrate closer to the $\mathrm{C}_{60}$ cage. If one extrapolates such speculation, it might be interesting to use larger, but less nucleophilic, basic anions, i.e., $\mathrm{EtO}^{-}, i-\mathrm{PrO}^{-}$, or tert- $\mathrm{BuO}^{-}$. It is, however, beyond our current research to test hydrolysis with higher alkylates.

\section{1. Molar Absorption Coefficient as a Mea- sure of the Degree of Partial Decarboxy- lation and/or Degree of Hydroxylation}

It is interesting to mention that until now we were not aware of possible nucleophilic addition of a base to the $\mathrm{C}_{60}$ skeleton during basic hydrolysis. Therefore, we were ascribing the occasional deviations of the value of the molar absorption coefficient obtained at $334 \mathrm{~nm}\left(\varepsilon_{334}\right)$ from the reported value $\left(\varepsilon_{334}=4.19 \times 10^{4} \mathrm{~L} /(\mathrm{cm}\right.$ mol $\left.\left._{\mathrm{FHMA}}\right)\right)^{27}$ to the differences in the partial decarboxylation. Namely, molar absorption coefficient of the synthesized sample was always determined from the measured absorbance and concentration of $T_{\mathrm{h}}$-FHMA, obtained by potentiometric neutralization titration. ${ }^{27}$ Having in mind the fact that the number of $-\mathrm{COOH}$ groups attached to $\mathrm{C}_{60}$, can be lower than 12 (because of the partial decarboxylation), it is easy to understand that $\varepsilon_{334}$, calculated from the concentration of $-\mathrm{COOH}$ groups, also depends on the degree of partial decarboxylation. Consequently, in the absence of hydroxylation of $\mathrm{C}_{60}$ skeleton, measured $\varepsilon_{334}$ could be used as a rough measure of the degree of partial decarboxylation, if one assumes that the influence of partial decarboxylation on electronic properties of fullerene $\pi$-chromophore system is negligible.

An occurrence of hydroxylation may have, in the worst case, the influence on the interpretation of experimental results, obtained with the help of molar absorption coefficient of $T_{\mathrm{h}}$-FHMA. ${ }^{9}$ Nevertheless, at the present we do not have any indications that this is the case. On the other hand, knowing the influence of the hydroxylation of the $\mathrm{C}_{60}$ skeleton on the shape of the UV/Vis and IR spectra is of notable help in the fast estimation of possible deterioration of the $T_{\mathrm{h}}-\mathrm{C}_{66}(\mathrm{COOEt})_{12}$ sample.

\section{Conclusions}

UV/Vis and IR spectra of the hydrolysed samples of $T_{\mathrm{h}}-\mathrm{C}_{66}(\mathrm{COOEt})_{12}$ clearly demonstrate that additional hydroxylation of the $T_{\mathrm{h}}$-symmetric fullerenehexamalonic acid $\left(T_{\mathrm{h}}\right.$-FHMA) can take place during the basic hydrolysis. This is, beside the already known partial decarboxylation, ${ }^{9}$ another side reaction that aggravates preparation of pure samples of $T_{\mathrm{h}}$-FHMA and its salts. The conditions at which hydroxylation of fullerene core of $T_{\mathrm{h}}$-FHMA occurs, are considerably milder than those usually used in the preparation of $\mathrm{C}_{60}$ fullerenols. One of the reasons for easier nucleophilic addition of - $\mathrm{OH}$ groups may be good solubility of polar $T_{\mathrm{h}} \mathrm{C}_{66}(\mathrm{COOEt})_{12}$ molecule in acetone, which allows the hydroxylation to occur in a one-phase system, compared to the two-phase hydroxylation in the case of parent non-polar $\mathrm{C}_{60}$. Furthermore, the assistance of six malonate carboxylic groups, attached on the $\mathrm{C}_{60}$ core, additionally promoting the nucleophilic attack of $-\mathrm{OH}$ ions, could also be taken into account.

Although UV/Vis and IR spectrometry may give qualitative or even semi-quantitative information about the occurrence of hydroxylation reaction on the $\mathrm{C}_{60}$ skeleton, the quantitative estimation can be obtained only by the use of additional methods and systematic elucidation of results from all of the used methods. Inclusion of ionchromatography and capillary electrophoresis in such a study seems to be indispensable. ${ }^{9}$

One should take into account that $T_{\mathrm{h}}$-symmetric hexakis adducts are not the only fullerene-based compounds with rather typical shape of UV/Vis spectrum. ${ }^{21}$ Therefore, the use of UV/Vis and IR spectroscopy as a fast and inexpensive monitoring tool might be of help also for other investigations where additions on $\mathrm{C}_{60}$ skeleton of molecules with distinct absorption spectra take place. 


\section{Acknowledgement}

Financial support by the Slovenian Research Agency through Grant No. P1-0201 and P1-0230 is gratefully acknowledged.

\section{References}

1. M. S. Dresselhaus, G. Dresselhaus, P. C. Eklund, Science of fullerenes and carbon nanotubes. Academic Press: San Diego, 1996; pp. 870-917. http://dx.doi.org/10.1016/B978-012221820-0/50020-4

2. S. Bosi, T. Da Ros, G. Spalluto, M. Prato, Eur. J. Med. Chem. 2003, 38, 913-923. http://dx.doi.org/10.1016/j.ejmech.2003.09.005

3. J. Cerar, J. Škerjanc, J. Phys. Chem. B 2008, 112, 892-895. http://dx.doi.org/10.1021/jp076492k

4. J. Cerar, T. Urbic, J. Phys. Chem. B 2008, 112, 1224012248. http://dx.doi.org/10.1021/jp801132e

5. S. A. Allison, H. F. Wu, A. Moyher, L. Soegiarto, B. T. D. Nguyen, T. Nguyen, D. Park, J. Phys. Chem. B 2014, 118, 3150-3155. http://dx.doi.org/10.1021/jp500196j

6. J. Cerar, J. Škerjanc, Acta Chim. Slov. 2001, 48, 375-383.

7. J. Škerjanc, J. Chem. Phys. 1999, 110, 6890-6895. http://dx.doi.org/10.1063/1.478594

8. J. Škerjanc, Acta Chim. Slov. 2012, 59, 559-563.

9. J. Cerar, M. Pompe, M. Guček, J. Cerkovnik, J. Škerjanc, J. Chromatogr. A 2007, 1169, 84-96. http://dx.doi.org/10.1016/j.chroma.2007.08.044

10. a) N. O. Mchedlov-Petrossyan, Chem. Rev. 2013, 113, 5149-5193. http://dx.doi.org/10.1021/cr3005026

b) For early fundamental report on addition of hydroxide ions to the fullerene skeleton, see: A. Naim, P. B. Shevlin, Tetrahedron Lett. 1992, 33, 7097-7100. http://dx.doi.org/10.1016/S0040-4039(00)60845-6

11. R. B. Sardenberg, C. E. Teixeira, M. Pinheiro, J. M. A. Figueiredo, ACS Nano 2011, 5, 2681-2686. http://dx.doi.org/10.1021/nn102913p

12. K. N. Semenov, N. A. Charykov, V. N. Keskinov, J. Chem. Eng. Data 2011, 56, 230-239. http://dx.doi.org/10.1021/je100755v

13. Y. B. Sun, C. Y. Cao, S. L. Yang, P. P. Huang, C. R. Wang, W. G. Song, Chem. Commun. 2014, 50, 10307-10310. http://dx.doi.org/10.1039/C4CC04891A

14. P. Chaudhuri, A. Paraskar, S. Soni, R. A. Mashelkar, S.
Sengupta, ACS Nano 2009, 3, 2505-2514. http://dx.doi.org/10.1021/nn900318y

15. R. Injac, N. Radic, B. Govedarica, A. Djordjevic, B. Strukelj, Afr. J. Biotechnol. 2008, 7, 4940-4950.

16. K. Kokubo, K. Matsubayashi, H. Tategaki, H. Takada, T. Oshima, ACS Nano 2008, 2, 327-333. http://dx.doi.org/10.1021/nn700151z

17. P. A. Indeglia, A. Georgieva, V. B. Krishna, J. C. J. Bonzongo, J. Nanopart. Res. 2014, 16, Article Number: 2599. http://dx.doi.org/10.1007/s11051-014-2599-4

18. I. Lamparth, C. Maichle-Mössmer, A. Hirsch, Angew. Chem.-Int. Edit. Engl. 1995, 34, 1607-1609. http://dx.doi.org/10.1002/anie.199516071

19. J. Li, A. Takeuchi, M. Ozawa, X. H. Li, K. Saigo, K. Kitazawa, J. Chem. Soc.-Chem. Commun. 1993, 1784-1785. http://dx.doi.org/10.1039/c39930001784

20. F. Cardullo, P. Seiler, L. Isaacs, J. F. Nierengarten, R. F. Haldimann, F. Diederich, T. Mordasini-Denti, W. Thiel, C. Boudon, J.-P. Gisselbrecht, M. Gross, Helv. Chim. Acta 1997, 80, 343-371.

http://dx.doi.org/10.1002/hlca.19970800203

21. A. Hirsch, I. Lamparth, T. Grosser, H. R. Karfunkel, J. Am. Chem. Soc. 1994, 116, 9385-9386. http://dx.doi.org/10.1021/ja00099a088

22. a) A. Arrais, E. Diana, R. Rossetti, E. Boccaleri, Carbon 2007, 45, 2502-2510. http://dx.doi.org/10.1016/j.carbon.2007.08.027

b) A. Arrais, E. Diana, Fullerenes, Nanotubes and Carbon Nanostructures 2003, 11, 35-46. http://dx.doi.org/10.1081/FST-120018667

23. I. Lamparth, Additionreaktionen und Gerüstmodifikationen des Buckminsterfullerene C60. Doctoral Thesis, Universität Erlangen-Nürnberg, Erlangen, 1996.

24. D. Y. Sun, Z. Y. Liu, X. H. Guo, Y. M. She, Y. Zhou, S. Y. Liu, Chin. Chem. Lett. 1996, 7, 431-432.

25. A. Astefaneia, O. Núñeza, M. T. Galceran, Anal. Chim. Acta http://dx.doi.org/10.1016/j.aca.2015.03.025

26. a) A. T. Georgieva, V. Pappu, V. Krishna, P. G. Georgiev, I. Ghiviriga, P. Indeglia, X. Xu, Z. H. Fan, B. Koopman, P. M. Pardalos, B. Moudgil, J. Nanopart. Res. 2013, 15, Article Number: 1690. http://dx.doi.org/10.1007/s11051-013-1690-6 b) T.-C. Chao, G. Song, N. Hansmeier, P. Westerhoff, P. Herckes, R. U. Halden, Anal. Chem. 2011, 83, 1777-1783. http://dx.doi.org/10.1021/ac1031379

27. J. Cerar, J. Cerkovnik, J. Škerjanc, J. Phys. Chem. B 1998, 102, 7377-7381. http://dx.doi.org/10.1021/jp982484f

\section{Povzetek}

Prispevek poroča o neposredni nukleofilni adiciji-OH skupin na $\mathrm{C}_{60}$ skelet pri bazični hidrolizi etilnega estra $T_{h}$-simetrične fulerenheksamalonske kisline ( $T_{h}$-FHMA) kot pomembni stranski reakciji. Pri tem nastane hibridna molekula, ki ima lastnosti tako $T_{h}$-FHMA kot tudi fulerenola. Hidroksiliranje poteka pri bistveno milejših pogojih, kot se običajno uporabljajo pri sintezi $\mathrm{C}_{60}$ fulerenolov. Za hitro zasledovanje reakcij in analizo sta bili uspešno uporabljeni UV/Vis in IR spektroskopija. Obe analizni metodi lahko s pridom uporabimo tudi pri drugih raziskavah, kjer potekajo reakcije adicije na skelet $\mathrm{C}_{60}$ molekul z značilnim absorpcijskim spektrom. 